\title{
A new device for minimally invasive mechano- -chemical method of saphenous vein ablation. Report of 12 months of follow up
}

\author{
Marek Iłżecki', Piotr Terlecki', Stanisław Przywara', Tomasz Urbanek², \\ Agnieszka Pedrycz-Wieczorska ${ }^{3}$, Shawn Dave ${ }^{4}$, Tomasz Zubilewicz' \\ 'Chair and Department of Vascular Surgery and Angiology, Medical University of Lublin, Poland \\ ${ }^{2}$ Upper Silesian Medical Center, Hospital in Ochojec, Department of General Surgery, Vascular Surgery, \\ Phlebology, Ochojec, Poland \\ ${ }^{3}$ Chair and Department of Histology and Embryology with the Laboratory Experimental Cytology of the Medical University \\ of Lublin, Poland \\ ${ }^{4}$ Hope Medical Institute, Virginia, USA
}

\begin{abstract}
Introduction. The purpose of the study was to assess the effectiveness of endovascular mechanochemical ablation of the Great Saphenous vein and the Small Saphenous vein (GSV/SSV) using the use of Flebogrif ${ }^{\oplus}$ catheter and method, based on results obtained from the analysis of 200 patients.

Material and methods. 200 patients underwent mechanochemical ablation using the Flebogrif technique, of the 200 patients, 172 patients experienced insufficiency of the GSV and 28 experienced insufficiencies of the SSV. Follow-up assessment was established by outpatient appointments at I, 3, 6, and I 2 months postoperatively. During each subsequent visit, the result of the procedure was evaluated with the use of ultrasound. Furthermore, the intensity of clinical manifestations was assessed with the use of VCSS, CEAP, VASP scales. Any complications were also noted.
\end{abstract}

Results. During 12-month follow-up the number of participants decreased to 168 (I52 female, 16 male). Complete closure of the vein was achieved in 154 patients (I 40 female, 14 male). According to adopted criteria, 15 cases of recanalization were detected ( 10 complete and 5 partial). Based on the obtained results the effectiveness of the method was assessed at $92 \%$.

Conclusions. The statistical analysis of the 12-month follow-up data allowed us to conclude the following the procedural method had $92 \%$ of effectiveness at I 2 -month follow-up, vein diameter was not a significant limitation for the application of the technique, there was a low rate of serious complications, and adverse cosmetic effect was minimal. However, the method requires further long-term follow-up to allow for a complete assessment.

Key words: mechanochemical ablation, endovascular procedures, Flebogrif ${ }^{\circledR}$, varices, obliteration

Acta Angiol 2018; 24, 3: 67-73

Address for correspondence: Marek Itżecki, Chair and Department of Vascular Surgery and Angiology, Medical University of Lublin, Staszica II, 20-08I Lublin, Poland, e-mail: milzecki@interia.pl 


\section{Introduction}

The significant number of patients presenting with chronic venous insufficiency remains an inspiration for further search of an effective therapeutic method associated with long-lasting effectiveness, high level of safety, and broad accessibility [I, 2]. Endovascular thermal ablation techniques introduced in the early 1990s utterly transformed vein surgery, resulting in a new minimally invasive approach [3]. The procedures gained the approval of both patients and physicians [4]. Due to their high efficacy and reproducibility of the outcome, they remain the most commonly used procedures for endovascular GSV/SSV ablation [4]. Our proposed method of endovascular mechanochemical GSV/SSV ablation with the use of Flebogrif ${ }^{\circledR}$ catheter is an effective, minimally invasive treatment of venous insufficiency [5]. The model pathological mechanism of Flebogrif $\AA$ method is based on shrinking of the veins, and the resultant fibrosis due to the inflammatory process as a consequence of chemical damage to the endothelium initialized by mechanical injury of the vessel wall.

The main goal of this study was to assess: the effectiveness of mechanochemical ablation of the GSV/ /SSV using the Flebogrif catheter (expressed as the percentage of fully closed veins). Clinical effectiveness based on the evaluation of the intensity of clinical signs at fixed follow-up intervals, using the VCSS, CEAP, VAPS scales, and safety of the procedure, based on the analysis of the type and clinical significance of observed complications were also assessed.

\section{Material and methods}

200 patients underwent surgical procedures from January 2013 to December 2015 due to Great Sa- phenous Vein (GSV) and Small Saphenous Vein (SSV) insufficiency. Tables I and 2 present the demographic data the respective number of participants during the 12 month follow-up period.

The study was performed after obtaining approval from the Ethics Committee at the Medical University of Lublin. The analyzed patients met all the inclusion criteria, and no exclusion criteria were established. After signing the consent form, each patient underwent an ultrasound to confirm the insufficiency of the GSV/ /SSV. Special attention was given to such deep vein pathologies, such as post-thrombotic changes, partial obstruction, and total occlusion. The ultrasound was completed while in a standing position. Ascertaining the length of the insufficient vein helped to better determine the proper site for the puncture of the vessel. In the case of the GSV the optimal puncture site location was the lowest point in the segment of the insufficient vein, whereas the SSV was punctured maximally peripherally in relation to sapheno-popliteal junction. Table 3 shows the diameter, number and location of the operated veins.

During the preoperative assessment (baseline), the intensity of clinical signs reflecting illness severity was collected and analyzed. The procedures were performed in a conventionally equipped operating room. In cases of GSV insufficiency, the patient was placed in a supine position, whereas in SSV cases, in a prone position was preferred. The procedure was performed with a prepared set, consisting of I8G needle, 0,035 "J angulated wire”, $6 \mathrm{Fr}$ vascular sheath, 2 syringes with a connector and a $6 \mathrm{Fr}$ Flebogrif ${ }^{\circledR}$ catheter. Before use, all the equipment was flushed with saline. Under ultrasound guidance, the vein was punctured with I8G needle at the level determined preoperatively. The introducer was inserted through venous cannula and its

Table I. Demographic data of the investigated group of patients

\begin{tabular}{|c|c|c|c|c|c|}
\hline \multirow[t]{2}{*}{ Gender } & \multirow[t]{2}{*}{ Number of patients } & \multicolumn{3}{|c|}{ Age } & \multirow[t]{2}{*}{ Total number of patients } \\
\hline & & Max & Average & Minimum & \\
\hline Females & 170 & 87 & 56 & 18 & \multirow{2}{*}{200} \\
\hline Males & 30 & 75 & 46 & 23 & \\
\hline
\end{tabular}

Table 2. Number of patients over 12 months of observation

\begin{tabular}{|c|c|c|c|c|c|}
\hline Patients $\begin{array}{c}\text { Postoperative } \\
\text { time }\end{array}$ & Baseline day „0" & I month & 3 month & 6 month & 12 month \\
\hline Number & 200 & 198 & 182 & 179 & 174 \\
\hline Females & 170 & 170 & 158 & 157 & 156 \\
\hline Males & 30 & 28 & 24 & 22 & 18 \\
\hline
\end{tabular}


Table 3. Diameter, number, and the side of puncture of operated veins

\begin{tabular}{|c|c|c|c|c|c|c|c|c|}
\hline \multicolumn{3}{|c|}{ The diameter of the vein (from-to/average) } & \multicolumn{4}{|c|}{ Number of operated limbs } & \multicolumn{2}{|c|}{ Proportion } \\
\hline \multirow[t]{2}{*}{ Below SFJ } & \multirow[t]{2}{*}{ Mid-thigh } & \multirow[t]{2}{*}{ Knee level } & \multicolumn{2}{|c|}{ Females } & \multicolumn{2}{|c|}{ Males } & \multirow[t]{2}{*}{ GSV } & \multirow[t]{2}{*}{ SSV } \\
\hline & & & Right & Left & Right & Left & & \\
\hline 4,2 & $3,8-17,1 / 6,2$ & $3,8-11,9 / 6,6$ & 68 & 102 & 13 & 17 & $172(86 \%)$ & $28(14 \%)$ \\
\hline
\end{tabular}

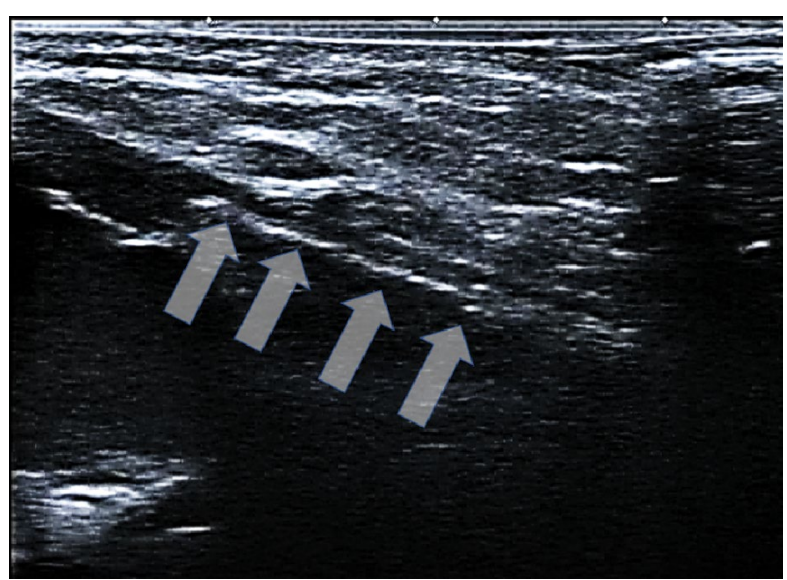

Figure I. The ultrasound view of working part of the Flebogrif $^{\circledR}$

tip was advanced to the level of the Sapheno-Femoral junction in GSV cases and the Sapheno-Popliteal junction in SSV cases. Before inserting the vascular sheath, the skin was anaesthetized with I ml of I\% Lignocaine. A small skin incision at the puncture site facilitated its

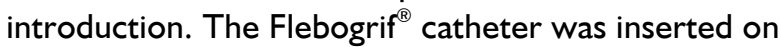
the introducer through the vascular sheath, and its tip was positioned $2 \mathrm{~cm}$ from Sapheno-Femoral junction. Maintaining this distance prevented the application of obliterating agent into the femoral vein. Proper position of the Flebogrif ${ }^{\circledR}$ was confirmed by ultrasound (Fig. I). By retracting the outer sheath, five cutting elements were released. The hooked tips of these elements "bit" into the venous wall. A crucial aspect of the procedure was to withdraw the Flebogrif ${ }^{\circledR}$ catheter at a constant speed of $5 \mathrm{~cm} / \mathrm{s}$ with simultaneous injection of a frothed obliterating agent, $3 \%$ Polidocanol, which was prepared according to the Tessari method ( $\mathrm{I} \mathrm{ml}$ of sclerosing agent mixed with $4 \mathrm{ml}$ of air). To maintain its proper consistency, the obliterating substance was prepared directly before its application. The construction of the catheter and functions of its constituent parts are presented in Figure 2.

The volume of $3 \%$ of foam applied did not exceed $10 \mathrm{ml}$ (I ampule/60 mg of pure Polidocanol frothed according to Tessari method in $1: 4$ ratio). Small varices were closed at the same time with $1 \%$ foam. However, the entire (main vein trunk + varices) amount
A

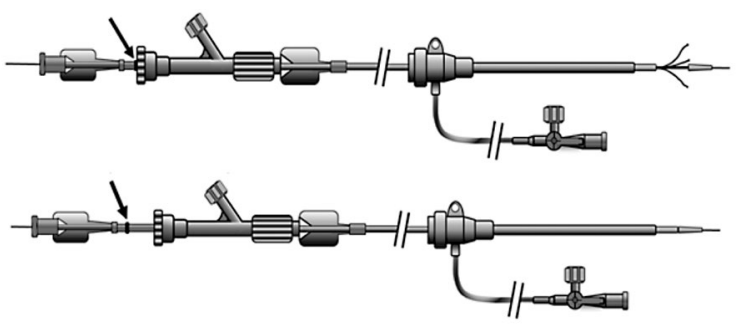

Figure 2. A - working part (cutting elements) - of the Flebogrif ${ }^{\circledR}$ is advanced forward; B - Working part (cutting elements) withdrawn into the catheter. The black ring at the proximal end of the catheter (see the black arrow in the Figure) indicates the position of the working part.

of obliterating agent did not exceed I mg/kg. Larger varicose veins requiring a larger volume of sclerosant were obliterated in the next session. The estimated volume of foamed substance administered to the vein lumen was I $\mathrm{ml}$ per $5 \mathrm{~cm}$ of vein. The maximum amount of Palidocanol used was $10 \mathrm{ml}$, and the minimum was $4 \mathrm{ml}$. Postoperatively, every patient was fitted with a compression stocking with a pressure of $20-30 \mathrm{~mm} \mathrm{Hg}$. The patient was advised to use the compression stocking continuously for $24 \mathrm{hrs}$ after the procedure as well as during the daytime for 4 weeks following the intervention. Each patient returned to normal physical activity immediately after the procedure and was discharged home within the following hour. Follow-up appointments were planned for I, 3, 6, 12, 24, and 36 months postoperatively.

\section{Obtained data analysis}

During arranged follow-up visits, evaluation of each patient clinical condition was performed with the use of the VCSS, CEAP scales, in combination with the visual analogue pain scale. Obtained data from the VCSS, CEAP and VAP scale underwent statistical analysis using the Friedman ANOVA test. Regarding the VCSS scale, a statistically significant decrease in clinical signs was observed in comparison to day " 0 " (baseline) $(p<0,00 \mathrm{I})$. No statistically significant differences were observed between the evaluation at 6 and 12 months. Table 4 presents the statistical characteristics of the obtained data. 
Table 4. Statistical analysis for the assessment using the VCSS scale

\begin{tabular}{|l|c|c|c|c|c|c|c|}
\hline & $\mathbf{n}$ & Min & \multicolumn{1}{c}{ Max } & M SD & Me & P \\
\hline VCSS - B & 200 & 3.00 & 21.00 & 10.72 & 3.96 & 9.00 & \\
\hline VCSS - I & 182 & 2.00 & 19.00 & 8.08 & 3.88 & 7.00 \\
\hline VCSS - 3 & 179 & 1.00 & 16.00 & 5.79 & 3.52 & 5.00 & $<0.001$ \\
\hline VCSS - 6 & 174 & 0.00 & 15.00 & 4.75 & 3.13 & 4.00 & \\
\hline VCSS - I2 & 168 & 0.00 & 15.00 & 4.40 & 2.94 & 4.00 & \\
\hline
\end{tabular}

n: number; min: minimum; max: maximum; M: mean; SD: standard deviation; Me: median

Table 5. Statistical analysis for the assessment using the CEAP scale

\begin{tabular}{|c|c|c|c|c|c|c|c|}
\hline & $\mathbf{n}$ & $\min$ & $\max$ & $\mathbf{M}$ & SD & Me & $\mathbf{p}$ \\
\hline$C E A P-b$ & 200 & 2.00 & 14.00 & 7.62 & 2.71 & 7.00 & \multirow{5}{*}{$<0.001$} \\
\hline CEAP - I & 182 & 1.00 & 12.00 & 5.48 & 2.54 & 5.00 & \\
\hline CEAP -3 & 179 & 0.00 & 10.00 & 3.70 & 2.28 & 3.00 & \\
\hline CEAP -6 & 174 & 0.00 & 10.00 & 3.20 & 2.13 & 3.00 & \\
\hline CEAP -12 & 168 & 0.00 & 10.00 & 2.99 & 2.05 & 3.00 & \\
\hline
\end{tabular}

n: number; min: minimum; max: maximum; M: mean; SD: standard deviation; Me: median

Table 6. Statistical analysis for the assessment of using the VAPS scale within 12 months follow-up

\begin{tabular}{|c|c|c|c|c|c|c|c|}
\hline & $\mathbf{n}$ & $\min$ & $\max$ & $M$ & SD & $\mathrm{Me}$ & $\mathbf{p}$ \\
\hline VAPS - b & 200 & 0.00 & 8.00 & 3.23 & 1.75 & 3.00 & \multirow{5}{*}{$<0.001$} \\
\hline VAPS - I & 182 & 0.00 & 7.00 & 1.88 & 1.43 & 1.00 & \\
\hline VAPS - 3 & 179 & 0.00 & 6.00 & 0.92 & 1.22 & 1.00 & \\
\hline VAPS - 6 & 174 & 0.00 & 6.00 & 0.72 & 1.06 & 0.00 & \\
\hline VAPS -12 & 167 & 0.00 & 4.00 & 0.60 & 0.86 & 0.00 & \\
\hline
\end{tabular}

n: number; min: minimum; max: maximum; M: mean; SD: standard deviation; Me: median

Table 7. The correlations between the diameter, length of the vein, the amount of foam and the full recanalization in the rang Spearman table

\begin{tabular}{|l|c|c|c|c|}
\hline Feature & Diameter SFJ & Diameter GSV & V foam & L vein \\
\hline Diameter SFJ & - & $\mathbf{0 . 6 6 0 8}$ & 0.4200 & -0.0389 \\
\hline Diameter GSV & $\mathbf{0 . 6 6 0 8}$ & & $\mathbf{0 . 8 0 0 2}$ & -0.0548 \\
\hline V foam & 0.4200 & $\mathbf{0 . 8 0 0 2}$ & & 0.2643 \\
\hline L vein & -0.0389 & -0.0548 & 0.2643 & - \\
\hline
\end{tabular}

Similarly, data from the evaluation of clinical state with the CEAP scale was statistically analyzed. A statistically significant decrease in clinical sign intensity was observed at follow-up points in relation to point " 0 " (baseline) ( $\mathrm{p}<0.00 \mathrm{I})$. No statistically significant differences were found between $6^{\text {th }}$ and $12^{\text {th }}$ month follow-up. Table 5 shows the statistical analysis of the CEAP scale.

Data obtained from the visual analogue pain scale show a statistically significant drop at follow-up time points in comparison to the initial point " 0 ", with a significance level of $p<0.00 \mathrm{I}$. The difference between $6^{\text {th }}$ and $12^{\text {th }}$ month follow-up points was not statistically significant (Table 6, Fig. 5.)

The impact of the diameter of the closed vein with the Flebogrif ${ }^{\circledR}$ catheter was also analyzed. The type of recanalization is not differentiated statistically significantly age, diameter, Sapheno-Femoral junction as well as the diameter of the trunk of Great Saphenous Vein, volume of the foam, and the length of the vein. Correlations were evaluated using rang Spearman table (Tables 6, 7). 


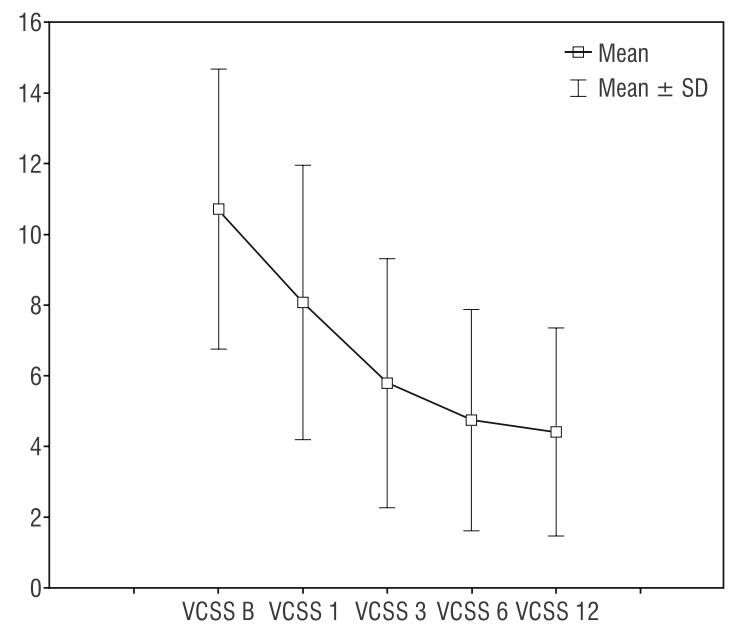

Figure 3. The time after surgery and VCSS values

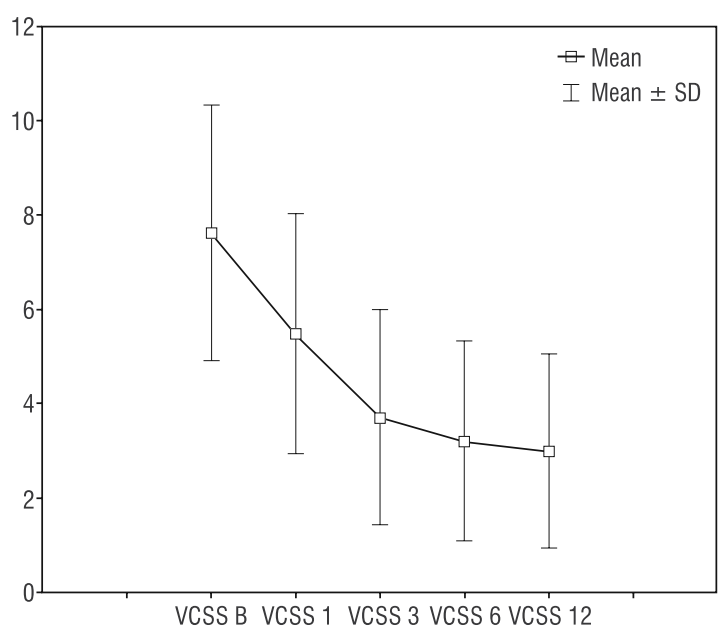

Figure 4. Postoperative time and the values of CEAP scale

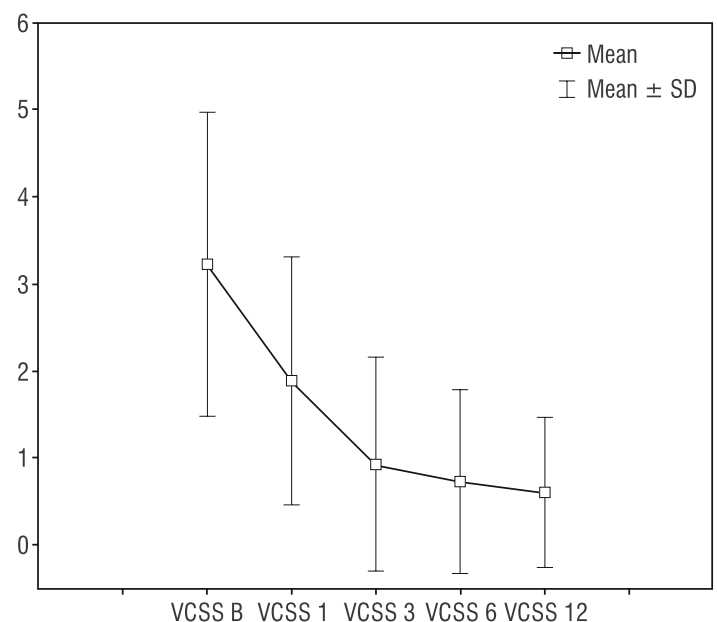

Figure 5. The time after surgery and values VAPS scale within 12 months follow-up

During the follow-up period, I 5 cases of recanalization were observed. According to the European Consensus for Sclerotherapy, the following criteria were adopted for complete recanalization: no change in the ablated vein's diameter, full patency of the vessel, reflux over $0.5 \mathrm{~s}$. Whereas partial recanalization was defined as a reduction in vein diameter, and reflux below $0.5 \mathrm{~s}$. The analysis of observed cases enabled classification of 10 cases as complete recanalization and 5 as partial recanalization. Table 7 shows the distribution of recanalized veins. Based on I2-month follow-up analysis, method efficacy was evaluated to be at $92 \%$.

\section{Discussion}

The method of endovascular ablation using the Flebogrif $^{\circledR}$ catheter is another effective way of solving

Table 8. The correlations between the diameter, length of the vein, the amount of foam and the full occlusion in the rang Spearman table

\begin{tabular}{|c|c|c|c|c|}
\hline Feature & Diameter SFJ & Diameter GSV & $V$ foam & L vein \\
\hline Diameter SFJ & & 0.7800 & 0.3126 & 0.0823 \\
\hline Diameter GSV & 0.7800 & & 0.3011 & 0.0428 \\
\hline$V$ foam & 0.3126 & 0.3011 & & 0.8366 \\
\hline$L$ vein & 0.0823 & 0.0428 & 0.8366 & \\
\hline
\end{tabular}

Table 9. The cases of recanalized veins in relation to diameter of the vein, puncture site and amount of given foam

\begin{tabular}{|c|c|c|c|c|c|c|c|c|c|c|c|}
\hline \multirow{3}{*}{ Gender } & \multirow{2}{*}{\multicolumn{2}{|c|}{$\begin{array}{c}\text { Recanalization } \\
\text { GSV } \\
\end{array}$}} & \multirow{2}{*}{\multicolumn{2}{|c|}{$\begin{array}{c}\text { Recanalization } \\
\text { SSV }\end{array}$}} & \multicolumn{2}{|c|}{ V. Diameter } & \multicolumn{3}{|c|}{ Puncture site } & \multirow{2}{*}{\multicolumn{2}{|c|}{$\begin{array}{c}\text { Volume of } \\
\text { sclerosing agent }(\mathrm{ml})\end{array}$}} \\
\hline & & & & & & & & & & & \\
\hline & $\mathbf{L}$ & $\mathbf{R}$ & $\mathbf{L}$ & $\mathbf{R}$ & Form - to $(\mathrm{mm})$ & Average & Above & Knee & Belove & GSV & SSV \\
\hline Females & 7 & 1 & 4 & - & $5.8-20.1$ & 13.1 & 2 & 4 & 7 & $4-8$ & $2-5$ \\
\hline Male & 2 & 1 & - & - & $6.8-10.0$ & 11.4 & 0 & 0 & 2 & $5-8$ & - \\
\hline
\end{tabular}


the problem of chronic vein insufficiency [6]. During the last quarter of a century, several new methods (EVLT, RFA, among others) were introduced. These procedures effectively drew the attention of both the medical community and patients as an endovascular, minimally-invasive way of treating superficial venous drainage insufficiency (GSV/SSV) [4, 6-8]. This procedure became a valuable alternative to the classical Babcock method of vein stripping, combined with mini-phlebectomy, which has been the dominating method in the treatment of various until the end of the 1980's. In establishing the necessity of procedures we adopt the following criteria low cost, and thus better accessibility; short hospitalization with the possibility of outpatient intervention; and most importantly, safety as well as the permanence of therapeutic effect [2]. Certainly, both thermal methods and the recently introduced superheat approach fulfil these requirements [9]. Their undoubted advantage is short patient recovery time, very good cosmetic effect and, a relatively low number of complications, therefore results in a high quality of life index [10]. They are, however, a source of new types of complications such as neuralgia, hematomas, thermal injury of the skin. Additionally, this method requires tumescence which further complicates and prolongs the procedure [6]. At present, procedures with the use of a thermal factor (EVLR, RFA, STEAM) remain the most commonly performed procedures in cases of superficial venous trunk insufficiency $[2,3]$. Another minimally-invasive procedure is foam obliteration, either through a catheter or with direct vein puncture under ultrasound guidance $[8, \mathrm{II}]$. Although effectiveness assessed in randomized control trials is lower when compared to surgical treatment, its low level of invasiveness combined with low complication rate encourage its supporters to apply it in treatment [12]. The introduction of Flebogrif ${ }^{\oplus}$ to the European market opened a new chapter in the history of minimally-invasive procedures, especially since the procedure completely eliminates the need for tumescence manoeuvre as well as anaesthesia during the procedure $[5,13,14]$. At this point, it should be emphasized that Clarivein was historically the first procedure creating the mechanochemical group of procedures, which effectiveness and safety were confirmed in several studies [15-18]. Overall patients tolerated all the steps of the Flebogrif ${ }^{\circledR}$ procedure very well, and self-assessment of pain perception using a visual analogue scale allows as to generalize that the procedure is not painful. Another additional advantage of this method is quick return to the previous physical activity. In practice, patients who undergo the procedure Flebogrif $^{\circledR}$ are able to walk directly afterwards and are discharged home in the course of I hour. When starting the procedure, we have a prepackage set at our disposal which consists of all the necessary devices. Performing an analysis of the cost of this approach, revealed to be relatively low, thus making it more accessible for the arger cohort of patients relatively low, it more accessible for a large cohort of patients suffering from varices. Results obtained from 12-month follow-up demonstrated the highly efficacious nature of the procedure reaching $92 \%$. Although 15 of 200 patients experienced recanalization, some of them did not require reintervention- partial recanalization, whereas remaining 10 cases had their vein successfully closed with a second procedure. The low number of complications and a cosmetic effect widely accepted by patients allowed us to add this method to the list of minimally-invasive procedures and should be seriously considered by medical professionals treating superficial vein insufficiencies $[14,19,20]$.

\section{Conclusions}

Based on obtained results we were to summarize the following conclusions:

- high 12-month follow-up effectiveness reaching $92 \%$ of closed/ablated veins;

- vein diameter is not a limitation for this method;

- the low rate of serious complications;

- good cosmetic effect;

- the method requires further long-term follow-up to fully determine the actual effectiveness of the mechanochemical technique using Flebogrif ${ }^{\circledR}$, therefore obtained findings should be treated as preliminary.

\section{Conflict of interest}

None.

\section{References:}

I. Kiguchi MM, Dillavou ED. Thermal and nonthermal endovenous ablation options for treatment of superficial venous insufficiency. Surg Clin North Am. 2018; 98(2): 385-400, doi: 10.1016/j. suc.2017.1 1.014, indexed in Pubmed: 29502779.

2. van Eekeren RR, Boersma D, de Vries JPPM, et al. Update of endovenous treatment modalities for insufficient saphenous veins - a review of literature. Semin Vasc Surg. 2014; 27(2): | 18-136, doi: 10.1053/j.semvascsurg.2015.02.002, indexed in Pubmed: 25868763.

3. Leopardi D, Hoggan BL, Fitridge RA, et al. Systematic review of treatments for varicose veins. Ann Vasc Surg. 2009; 23(2): 264-276, doi: 10.1016/j.avsg.2008.10.007, indexed in Pubmed: 19059756.

4. van Eekeren RR, Boersma D, Elias S, et al. Endovenous mechanochemical ablation of great saphenous vein incompetence using the ClariVein device: a safety study. J Endovasc Ther. 20I I; 18(3): 328-334, doi: 10.1583/I I-3394.1, indexed in Pubmed: 21679070 
5. van den Bos RR, de Maeseneer M. Endovenous thermal ablation for varicose veins: strengths and weaknesses. Phlebolymphology. 2012; 19(4): 163-169.

6. Kurdal AT, Yildirim F, Ozbakkaloglu A, et al. Ultrasound-guided catheter-directed foam sclerotherapy for great saphenous vein. Minerva Chir. 2015; 70(I): 33-36, indexed in Pubmed: 2565065 I.

7. Göckeritz $O$. Current standards and recent progress in minimally invasive phlebo surgery. J Cutan Aesthet Surg. 2012; 5(2): 104-1 I4, doi: 10.4 103/0974-2077.99443, indexed in Pubmed: 23060705.

8. Elias S, Raines JK. Mechanochemical tumescentless endovenous ablation: final results of the initial clinical trial. Phlebology. 2012; 27(2): 67-72, doi: 10.1258/phleb.2011.010100, indexed in Pubmed: 21803800

9. Rabe E, Breu FX, Cavezzi A, et al. Guideline Group. European guidelines for sclerotherapy in chronic venous disorders. Phlebology. 20 I4; 29(6): 338-354, doi: I0.I I 77/02683555 I3483280, indexed in Pubmed: 23559590.

10. Vun SV, Rashid ST, Blest NC, et al. Lower pain and faster treatment with mechanico-chemical endovenous ablation using ClariVein ${ }^{\circledast}$. Phlebology. 2015; 30(10): 688-692, doi: I0.1 I77/02683555 |4553693, indexed in Pubmed: 253003 II.

II. Niedzwiecki G. Endovenous thermal ablation of the saphenous vein. Semin Intervent Radiol. 2005; 22(3): 204-208, doi: 10.1055/s-2005-921953, indexed in Pubmed: 21326694.

12. van Eekeren RR, Boersma D, Elias S, et al. Endovenous mechanochemical ablation of great saphenous vein incompetence using the ClariVein device: a safety study. J Endovasc Ther. 201 I; I8(3): 328-334, doi: 10.1583/II-3394. I, indexed in Pubmed: 21679070.

13. Badri H, Bhattacharya V. A review of current treatment strategies for varicose veins. Recent Pat Cardiovasc Drug Discov. 2008; 3(2): 126-136, indexed in Pubmed: 18537763.
14. Bootun R, Lane TRA, Dharmarajah B, et al. Intra-procedural pain score in a randomised controlled trial comparing mechanochemical ablation to radiofrequency ablation: The Multicentre Venefit $^{\mathrm{TM}}$ versus ClariVein ${ }^{\circledR}$ for varicose veins trial. Phlebology. 2016; 3I(I): 6I-65, doi: 10.1 I77/02683555I455I085, indexed in Pubmed: 25193822

15. Milleret R, Huot L, Nicolini P, et al. Great saphenous vein ablation with steam injection: results of a multicentre study. Eur J Vasc Endovasc Surg. 2013; 45(4): 39I-396, doi: 10.1016/j. ejvs.2013.01.027, indexed in Pubmed: 23410966.

16. Ciostek P, Kowalski M, Woźniak W, et al. Phlebogriffe - a new device for mechanochemical ablation of incompetent saphenous veins: a pilot study. Phlebological Review. 2015; 3: 72-77, doi: 10.5I I4/pr.20I5.57466.

17. Nijsten T, van den Bos RR, Goldman MP, et al. Minimally invasive techniques in the treatment of saphenous varicose veins. J Am Acad Dermatol. 2009; 60(1): 110-119, doi: 10.1016/j. jaad.2008.07.046, indexed in Pubmed: 18835063.

18. Witte ME, Reijnen MM, de Vries JP, et al. Mechanochemical Endovenous Occlusion of Varicose Veins Using the ClariVein ${ }^{\circledR}$ Device. Surg Technol Int. 2015; 26: 219-225, indexed in Pubmed: 26055013.

19. Zubilewicz T, Terlecki P, Przywara S, et al. Applications of mechanochemical ablation with Flebogrif to treat varicose veins of lower extrmities: a single center experience over 3 months observation. Acta Angiol. 2006; 22(4): 137-142.

20. Vos CG, Ünlü Ç, Bosma J, et al. A systematic review and meta-analysis of two novel techniques of nonthermal endovenous ablation of the great saphenous vein. J Vasc Surg Venous Lymphat Disord. 2017; 5(6): 880-896, doi: 10.1016/j.jvsv.2017.05.022, indexed in Pubmed: 29037363. 